\title{
New Directions in Healthcare for Alcohol Use Disorder
}

\section{Euihyeon $\mathrm{Na}^{1}$, Changwoo $\mathrm{Han}^{2}$ and Sungwon $\mathrm{Roh}^{3 *}$}

${ }^{1}$ Department of Psychiatry, Seoul National Hospital, 398 Neungdong-ro, Gwangjin-gu, Seoul, Korea

${ }^{2}$ Department of Psychiatry, Korea University Ansan Hospital, 123 Jeokgeum-ro, Danwon-gu, Ansan, Gyeonggi-do, Korea

${ }^{3}$ Department of Mental Health Research, Seoul National Hospital, 398 Neungdong-ro, Gwangjin-gu, Seoul, Korea

\begin{abstract}
Alcohol use disorder is a significant cause of the global health burden. Most of conventional strategies in the public healthcare system are based on screening and brief interventions. Although the approach has been shown their effectiveness, various challenges still remain. This paper focuses on the new directions of healthcare for alcohol use disorder regarding the population, methods, and environment.
\end{abstract}

Keywords: Alcohol; Healthcare; Women; Adolescent; Technology; Community

\section{Introduction}

Alcohol use disorder is a major psychiatric disorder as a significant contributor to the global health burden [1]. Considering its subthreshold misuse including harmful and hazardous alcohol use, the health burden may increase further [2,3]. With regard to the matters, the healthcare for alcohol addiction frequently has been embedded in a public health policy as a social issue. Most public strategies on reducing the alcohol-related problems are based on the use of screening and brief interventions $[4,5]$. Conventional Screening and Brief Interventions (SBIs) have shown their clinical and cost effectiveness [6,7]. However, there are still many challenges when it comes to providing aftercare with ongoing monitoring and providing opportunities for improvement to various population $[8,9]$. This paper focuses on current advances in healthcare for alcohol use disorder to overcome these barriers.

\section{Targeting New Population}

While middle-aged men have been the participants in a large number of alcohol intervention trials, the recent epidemiologic data highlighted the newer groups such as women and adolescents. Studies have suggested that there have been substantial increases in drinking and alcohol dependence among women with acceptability of their drinking $[10,11]$. Additionally, gender differences in alcohol dependence have diminished in recent cohorts, especially in countries where traditional gender roles have concurrently changed $[12,13]$. Adolescent drinking is not only about $7 \%$ of main risk factor of cause-specific disabilityadjusted life years (DALYs) for young people aged 10-24 years, but also one of clustered risk-taking behaviors including smoking, substance use, and risky sexual behavior [14,15]. If the young people start consuming alcohol, very higher are their risks to drink regularly, to develop an addiction, and to suffer or die from alcohol-related illness $[16,17]$. Moreover, the adolescent brain, especially hippocampus, may particularly be vulnerable to the effects of alcohol, thus neurocognitive damages can persist into adulthood [18]. A noticeable aspect is that only a small number of studies have done focusing on the intervention for these populations. Further research is needed to identify specialized management as well as to understand the effectiveness of established strategies in the aforementioned groups $[9,19]$.

\section{Use of Novel Technologies}

The studies have demonstrated that people with problematic alcohol use rarely seek help although continuing care for alcohol use is associated with better outcomes $[20,21]$. The results from two national surveys indicated that only $7.9 \%$ and $6.6 \%$ of the population who needed treatment for an alcohol problem received treatment at a specialty facility in the United States and South Korea, respectively $[22,23]$. The advanced electronic systems based on the internet and smartphones could possibly offer a way of addressing some of the barriers with greater flexibility and anonymity than conventional medical services [24]. Compared to traditional care, technology can provide personalized care using less time and be available at the moment of greatest need [25]. Since the growing evidence from randomized controlled trials and meta-analyses supports the ability of new approach to alcohol use disorder, it may be required to perform a further research on utilizing a larger sample with longer-terms of follow-up periods [24-27].

\section{Recognizing the Role of Communities}

Communities are considered as prevailing intervention fields with primary care and social networks to people. Primary care is a setting that could reach out to a broad range of people and focus on prevention, health promotion and longitudinal comprehensive care, in which alcohol-related problems can be managed like others addressed routinely in this setting [28]. Besides, many aspects of social network structure and function have been associated with outcomes of treatment of alcohol use disorders [29]. Still, the concern with the interaction between primary care and social networks is undervalued. The synergy between these two elements of community healthcare system would create more costeffective interventions when dealing with the alcohol-related problems.

\section{Conclusion}

The global burden of alcohol-related problems has threatened public health. The rise of certain groups of patients and the emergence of advanced technology have led to the necessity of new directions in healthcare for alcohol use disorder. Communities could generate more effective healthcare service for the interaction between primary care and social networks. Further studies need to identify the most promising strategies.

*Corresponding author: Sungwon Roh, MD, PhD. Department of Mental Health Research, Seoul National Hospital, Ministry of Health and Welfare. 398 Neungdong-ro, Gwangjin-gu, Seoul 04933, Korea Tel: +82-2-22040292; E-mail: swroh@korea.kr

Received September 14, 2015; Accepted October 29, 2015; Published November 07, 2015

Citation: Na E, Han C, Roh S (2015) New Directions in Healthcare for Alcohol Use Disorder. Health Care Current Reviews 3: 144. doi: 10.4172/2375-4273.1000144

Copyright: (c) $2015 \mathrm{Na} \mathrm{E}$, et al. This is an open-access article distributed under the terms of the Creative Commons Attribution License, which permits unrestricted use, distribution, and reproduction in any medium, provided the original author and source are credited. 
Citation: Na E, Han C, Roh S (2015) New Directions in Healthcare for Alcohol Use Disorder. Health Care Current Reviews 3: 144. doi: 10.4172/23754273.1000144

\section{References}

1. Whiteford HA, Degenhardt L, Rehm J, Baxter AJ, Ferrari AJ, et al. (2013) Global burden of disease attributable to mental and substance use disorders: findings from the Global Burden of Disease Study 2010. Lancet 382: 1575-1586.

2. Saunders JB1, Lee NK (2000) Hazardous alcohol use: its delineation as a subthreshold disorder, and approaches to its diagnosis and management. Compr Psychiatry 41: 95-103.

3. WHO (2000) International guide for monitoring alcohol consumption and related harm. Geneva. : World Health Organization.

4. Kaner EF, Dickinson HO, Beyer F, Pienaar E, Schlesinger C, et al. (2009) The effectiveness of brief alcohol interventions in primary care settings: a systematic review. Drug Alcohol Rev 28: 301-323.

5. Gual A, Sabadini MB (2011) Implementing alcohol disorders treatment throughout the community. Curr Opin Psychiatry 24: 203-207.

6. Jonas DE, Garbutt JC, Amick HR, Brown JM, Brownley KA, et al. (2012) Behavioral counseling after screening for alcohol misuse in primary care: a systematic review and meta-analysis for the U.S. Preventive Services Task Force. Ann Intern Med 157: 645-654.

7. Tariq L, van den Berg M, Hoogenveen RT, van Baal PH (2009) Costeffectiveness of an opportunistic screening programme and brief intervention for excessive alcohol use in primary care. PLoS One 4: e5696.

8. McLellan AT, Lewis DC, O'Brien CP, Kleber HD (2000) Drug dependence, a chronic medical illness: implications for treatment, insurance, and outcomes evaluation. JAMA 284: 1689-1695.

9. O'Donnell A, Anderson P, Newbury-Birch D, Schulte B, Schmidt C, et al. (2014) The impact of brief alcohol interventions in primary healthcare: a systematic review of reviews. Alcohol Alcohol 49: 66-78.

10. Grucza RA, Norberg K, Bucholz KK, Bierut LJ (2008) Correspondence between secular changes in alcohol dependence and age of drinking onset among women in the United States. Alcohol Clin Exp Res 32: 1493-1501.

11. Greenfield TK, Room R (1997) Situational norms for drinking and drunkenness: trends in the US adult population, 1979-1990. Addiction 92: 33-47.

12. Keyes KM, Martins SS, Blanco C, Hasin DS (2010) Telescoping and gender differences in alcohol dependence: new evidence from two national surveys. Am J Psychiatry 167: 969-976.

13. Seedat S, Scott KM, Angermeyer MC, Berglund P, Bromet EJ, et al. (2009) Cross-national associations between gender and mental disorders in the World Health Organization World Mental Health Surveys. Arch Gen Psychiatry 66:785-795.

14. Gore FM, Bloem PJ, Patton GC, Ferguson J, Joseph V, et al. (2011) Globa burden of disease in young people aged 10-24 years: a systematic analysis. Lancet 377: 2093-2102.

15. Wiefferink CH1, Peters L, Hoekstra F, Dam GT, Buijs GJ, et al. (2006) Clustering of health-related behaviors and their determinants: possible consequences for school health interventions. Prev Sci 7: 127-149.
16. DeWit DJ, Adlaf EM, Offord DR, Ogborne AC (2000) Age at first alcohol use: a risk factor for the development of alcohol disorders. Am J Psychiatry 157 745-750.

17. Buchmann AF, Schmid B, Blomeyer D, Becker K, Treutlein J, et al. (2009) Impact of age at first drink on vulnerability to alcohol-related problems: testing the marker hypothesis in a prospective study of young adults. J Psychiatr Res 43: $1205-1212$.

18. Welch KA, Carson A, Lawrie SM (2013) Brain structure in adolescents and young adults with alcohol problems: systematic review of imaging studies. Alcohol Alcohol 48: 433-444.

19. Patton R, Deluca P, Kaner E, Newbury-Birch D, Phillips T, et al. (2014) Alcoho screening and brief intervention for adolescents: the how, what and where of reducing alcohol consumption and related harm among young people. Alcohol Alcohol 49: 207-212

20. McLellan AT, McKay JR, Forman R, Cacciola J, Kemp J (2005) Reconsidering the evaluation of addiction treatment: from retrospective follow-up to concurrent recovery monitoring. Addiction 100: 447-458

21. Cunningham JA, Breslin FC (2004) Only one in three people with alcohol abuse or dependence ever seek treatment. Addict Behav 29: 221-223.

22. Substance Abuse and Mental Health Services Administration. (2014) Results from the 2013 National Survey on Drug Use and Health: Summary of National Findings, NSDUH Series H-48, HHS Publication No. (SMA) 14-4863. Rockville, MD: Substance Abuse and Mental Health Services Administration.

23. Seoul National University College of Medicine. (2012) The Epidemiologica Survey of Mental Disorders in Korea 2011. Seoul: Ministry of Health and Welfare.

24. Donoghue K, Patton R, Phillips T, Deluca P, Drummond C (2014) The effectiveness of electronic screening and brief intervention for reducing levels of alcohol consumption: a systematic review and meta-analysis. J Med Internet Res 16: e142.

25. Gustafson DH, McTavish FM, Chih MY, Atwood AK, Johnson RA, et al. (2014) A smartphone application to support recovery from alcoholism: a randomized clinical trial. JAMA Psychiatry 71: 566-572.

26. Riper $\mathrm{H}$, Blankers $\mathrm{M}$, Hadiwijaya $\mathrm{H}$, Cunningham J, Clarke $\mathrm{S}$, et al (2014) Effectiveness of guided and unguided low-intensity internet interventions for adult alcohol misuse: a meta-analysis. PLoS One 9: e99912.

27. Hester RK, Lenberg KL, Campbell W, Delaney HD. (2013) Overcoming Addictions, a Web-based application, and SMART Recovery, an online and inperson mutual help group for problem drinkers, part 1: three-month outcomes of a randomized controlled trial. J Med Internet Res 15: Edn134.

28. Gual A, Sabadini MB (2011) Implementing alcohol disorders treatment throughout the community. Curr Opin Psychiatry 24: 203-207.

29. McCrady BS (2004) To have but one true friend: implications for practice of research on alcohol use disorders and social network. Psychol Addict Behav 18: $113-121$ 